\title{
Ionic solid-impregnated sulphate-crosslinked chitosan for effective adsorption of hexavalent chromium from effluents
}

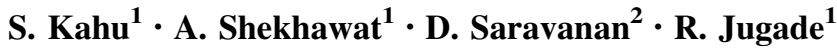

Received: 7 April 2015/Revised: 13 February 2016/ Accepted: 27 June 2016/Published online: 12 July 2016

(C) Islamic Azad University (IAU) 2016

\begin{abstract}
Microwave-assisted tetrabutyl ammonium-impregnated sulphate-crosslinked chitosan was synthesized for enhanced adsorption of hexavalent chromium. The adsorbent obtained was extensively characterized using Fourier transform infrared, X-ray diffraction, scanning electron microscopy and energy-dispersive X-ray studies. Various isotherm models such as Langmuir, Freundlich and Dubinin-Radushkevich were studied to comprehend the adsorption mechanism of hexavalent chromium by the adsorbent. Maximum adsorption capacity of $225.9 \mathrm{mg} \mathrm{g}^{-1}$ was observed at $\mathrm{pH} 3.0$ in accordance with Langmuir isotherm model. The sorption kinetics and thermodynamic studies revealed that adsorption of hexavalent chromium followed pseudo-second-order kinetics with exothermic and spontaneous behaviour. A column packed with $1 \mathrm{~g}$ of adsorbent was found to give complete adsorption of $\mathrm{Cr}(\mathrm{VI})$ up to $900 \mathrm{~mL}$ of $200 \mathrm{mg} \mathrm{L}^{-1}$ solution which discerns the applicability of the adsorbent material for higher sample volumes in column studies. The effective adsorption results were obtained due to both ion exchange and ion pair interaction of adsorbent with hexavalent chromium. Greener aspect of overall adsorption was regeneration of the adsorbent which was carried out using sodium hydroxide solution. In the present study, the regenerated adsorbent was effectively reused up to ten adsorptiondesorption cycles with no loss in adsorption efficiency.
\end{abstract}

R. Jugade

ravinj2001@yahoo.co.in

1 Department of Chemistry, R.T.M. Nagpur University, Nagpur 440033, India

2 Department of Chemistry, National College, Tiruchirappalli 620001, India
Keywords Biosorption - Carcinogen - Detoxification · Tetrabutyl ammonium bromide

\section{Introduction}

At present, heavy metal pollution in environment is of great concern towards the health of human beings. Chromium is not an omission. Generally chromium exists in trivalent $\mathrm{Cr}$ (III) and hexavalent $\mathrm{Cr}$ (VI) states. $\mathrm{Cr}$ (III) is an essential nutrient for human being, whereas $\mathrm{Cr}(\mathrm{VI})$ is a potent carcinogen (Katz and Salem 2006). Effluents from electroplating, tannery and dyeing industries contain Cr(VI) (Lewinsky 2007). Permissible limit of $\mathrm{Cr}(\mathrm{VI})$ in drinking water is $0.05 \mathrm{mg} \mathrm{L}^{-1}$. Therefore, there is a need to develop more effective methodology for detoxification of $\mathrm{Cr}(\mathrm{VI})$.

Chitosan is a natural polyaminosaccharide. Source material for chitosan is chitin which is the second most abundant biopolymer after cellulose. Chitin is an important constituent of some fungi and exoskeletons of crustaceans, molluscs and insects. Chitosan has monomer units of glucosamine and $N$-acetyl glucosamine linked by $\beta(1-4)$ glycosidic bonds. Its glucosamine content refers to the degree of deacetylation, and it is generally more than $60 \%$. Properties of chitosan such as biocompatibility, biodegradability and good adsorption tendency make it good material for wastewater treatment (Bhatnagar and Sillanpaa 2009).

Chitosan has gained pronounced attention in the field of biosorption that can be attributed to its chemical stability, high reactivity, excellent chelation behaviour and high selectivity towards pollutants (Elwakeel 2014; Geetha Devi et al. 2012). A modification of chitosan mainly involves the free-amine group on deacetylated units and hydroxyl 
groups on $C_{3}$ and $C_{6}$ carbons of monomers units (Kyzas and Bikiaris 2015). These groups of chitosan can be grafted or crosslinked with organic and inorganic moieties for removal of Cr(VI) (Debnath et al. 2014; Tirgar et al. 2006). A sulphate-crosslinked chitosan for detoxification of chromium has been prepared by Kahu et al. (2014). Anchoring of trialkyl amines on adsorbent has been reported in literature for the solid phase extraction of Cr(VI) (Kumar et al. 2015). Crosslinking provides mechanical strength and stability to the material while impregnation provides enhanced interaction with $\mathrm{Cr}(\mathrm{VI})$. Combination of these two modifications has a synergistic effect leading to improvement in adsorbent properties (Shekhawat et al. 2015).

Microwave-enhanced chemical reaction rates are faster than those of conventional heating methods and provide more effective means of energy transfer (Hayes 2004). Solvent-free preparation of surfactant-anchored cellulose towards chromium adsorption by using microwave irradiation has been reported by Kalidhasan et al. (2012). Microwave-assisted grafting of $n$-butyl acrylate on chitosan for $\mathrm{Cr}(\mathrm{VI})$ adsorption is an example of grafting on chitosan (Kumar et al. 2014a). In present study, tetrabutyl ammonium bromide-impregnated sulphate-crosslinked chitosan (TBA-SCC) has been synthesised by crosslinking polymer chains of chitosan with sulphate ions followed by impregnation of tetrabutyl ammonium bromide using microwave irradiation.

\section{Materials and methods}

This research project has been carried out in Analytical chemistry laboratory, Department of chemistry, R.T.M. Nagpur University, Nagpur from October 2014 to January 2015.

Tetrabutyl ammonium bromide (TBAB), Diphenyl carbazide, sulphuric acid, sodium hydroxide and potassium dichromate were procured from Merck, India. Aqueous solutions were prepared using double-distilled water. Uniloid Bio-Chemicals India Limited, Hyderabad, supplied chitosan having $85 \%$ of degree of deacetylation. All the reagents were of analytical grade and used without further purification.

\section{Preparation of TBAB-impregnated sulphate- crosslinked chitosan (TBA-SCC)}

Sulphate-crosslinked chitosan (SCC) was prepared as reported in the literature (Kahu et al. 2014); $5 \mathrm{~g}$ of chitosan powder was treated with $100 \mathrm{~mL}$ of $4 \% v / v$ sulphuric acid in a round bottom flask and stirred at room temperature for $1 \mathrm{~h}$. SCC obtained after filtration was washed several times with double-distilled water and dried at $333 \mathrm{~K}$ in hot air oven. An ordinary household microwave oven (LG India) was used for impregnation of TBAB on SCC. For this, $2.0 \mathrm{~g} \mathrm{SCC}$ was taken in conical flask and to it $5 \mathrm{~mL}$ of $0.5 \mathrm{M}$ TBAB solution in dichloromethane was added. The reaction mixture was stirred, and then it was subjected to microwave irradiation for 2 min with an intermittent time interval of $30 \mathrm{~s}$. The resulting residue (TBA-SCC) was washed with double-distilled water and dried at $333 \mathrm{~K}$ in hot air oven and was used for further adsorption studies.

\section{Physico-chemical characterization}

Structure of TBA-SCC could be explained on the basis of Fourier transform infrared (FTIR) spectra recorded using Bruker Alpha spectrometer in the range $500-4000 \mathrm{~cm}^{-1}$. The X-ray diffraction (XRD) pattern was recorded by X-ray diffractometer system Righaku-Miniflex 300. Surface morphology of adsorbent prior and consequent to adsorption of $\mathrm{Cr}(\mathrm{VI})$ was studied using scanning electron microscope (SEM) model TESCAN VEGA $3 \mathrm{SBH}$. Energy-dispersive spectral (EDX) analysis was performed for elemental quantitation using X-ray analyzer Oxford INCA Energy 250 EDS System during SEM observations.

Standard diphenylcarbazide method (Mendham et al. 2002) at $540 \mathrm{~nm}$ was utilized for spectrophometric determination of $\mathrm{Cr}(\mathrm{VI})$ concentration in solution phase after adsorption using Spectronic 20D+ spectrophotometer. $\mathrm{pH}$ adjustments were made with dilute sulphuric acid and sodium hydroxide solutions using an Equiptronics model EQ-615 pH meter.

\section{Adsorption procedure}

Adsorption studies were performed by using varying concentrations of $\mathrm{Cr}(\mathrm{VI})$ from 50 to $800 \mathrm{mg} \mathrm{L}^{-1}$ maintaining all the optimized parameters such as $\mathrm{pH}$, adsorbent dose and contact time and temperature constant.

The amount of $\mathrm{Cr}(\mathrm{VI})$ adsorbed $\left(\mathrm{mg} \mathrm{g}^{-1}\right)$ on TBA-SCC at equilibrium $\left(q_{\mathrm{e}}\right)$ can be given by

$q_{\mathrm{e}}=\frac{C_{0}-C_{\mathrm{e}}}{W} \times V$

where $C_{0}$ and $C_{\mathrm{e}}$ specify the initial and equilibrium liquidphase concentrations in $\mathrm{mg} \mathrm{L}^{-1}$ of $\mathrm{Cr}(\mathrm{VI}), V$ is the volume of $\mathrm{Cr}(\mathrm{VI})$ solution in litres, and $W$ is the weight of TBA-SCC in gram used for adsorption process. All the batch adsorption experiments were performed with three replicates.

\section{Desorption and reusability experiments}

The adsorbent along with adsorbed $\mathrm{Cr}(\mathrm{VI})$ was treated with $2 \% \mathrm{NaOH}$ solution to break down the impregnation as 
well as crosslinking in TBA-SCC and regenerate chitosan. This was further converted into TBA-SCC as explained above.

\section{Results and discussion}

\section{FTIR spectral characterization}

The FTIR spectral analysis (Fig. 1) showed distinct characteristic broad peaks corresponding to the various functional groups in chitosan and modified chitosan derivatives: $\mathrm{O}-\mathrm{H}$ and $\mathrm{N}-\mathrm{H}$ stretching vibrations in the region 3808 and $3276 \mathrm{~cm}^{-1}$, the $\mathrm{N}-\mathrm{H}$ bending vibration around $1556 \mathrm{~cm}^{-1}$, $\mathrm{C}-\mathrm{N}$ bending vibration at $1379 \mathrm{~cm}^{-1}$ and the $\mathrm{C}-\mathrm{H}$ and $\mathrm{C}-$ $\mathrm{O}$ stretching bands around 2868 and $1012 \mathrm{~cm}^{-1}$. In SCC, sulphate group peaks appeared at around $607 \mathrm{~cm}^{-1}$ in accordance with reported literature (Mayyas 2012). After impregnation with tetrabutyl ammonium bromide, two additional peaks were appeared at 2999 and $2805 \mathrm{~cm}^{-1}$ corresponding to the $-\mathrm{CH}_{2}$ groups of aliphatic chains confirming the impregnation. The quaternary ammonium ion of TBAB and sulphate ion of TBA-SCC are responsible for $\mathrm{Cr}(\mathrm{VI})$ adsorption. After adsorption of $\mathrm{Cr}(\mathrm{VI})$, a new peak was observed at $942 \mathrm{~cm}^{-1}$ which matches with reported value (Kumar et al. 2014b).

\section{XRD studies}

The diffraction patterns (Fig. 2) of SCC, TBA-SCC and with adsorbed $\mathrm{Cr}(\mathrm{VI})$ were recorded for characterization of adsorbent and to understand the feasibility of adsorption of $\mathrm{Cr}(\mathrm{VI})$ on adsorbent. XRD spectra of SCC showed characteristic peaks at $2 \theta=11.4^{\circ}, 18.2^{\circ}$ and $23.7^{\circ}$. In the case of TBA-SCC, these peaks were found to get shifted to $2 \theta=12.12^{\circ}, 19.0^{\circ}$ and $23.64^{\circ}$, respectively. These changes in the $2 \theta$ angle are mainly due to the decrease in crystallinity of the adsorbent which accounts for interaction of tetrabutyl ammonium bromide with SCC. After adsorption of $\mathrm{Cr}(\mathrm{VI})$ on TBA-SCC, an additional peak was observed at $2 \theta=26.8^{\circ}$ which matches with the reported value for $\mathrm{Cr}(\mathrm{VI})$ (Kahu et al. 2014).
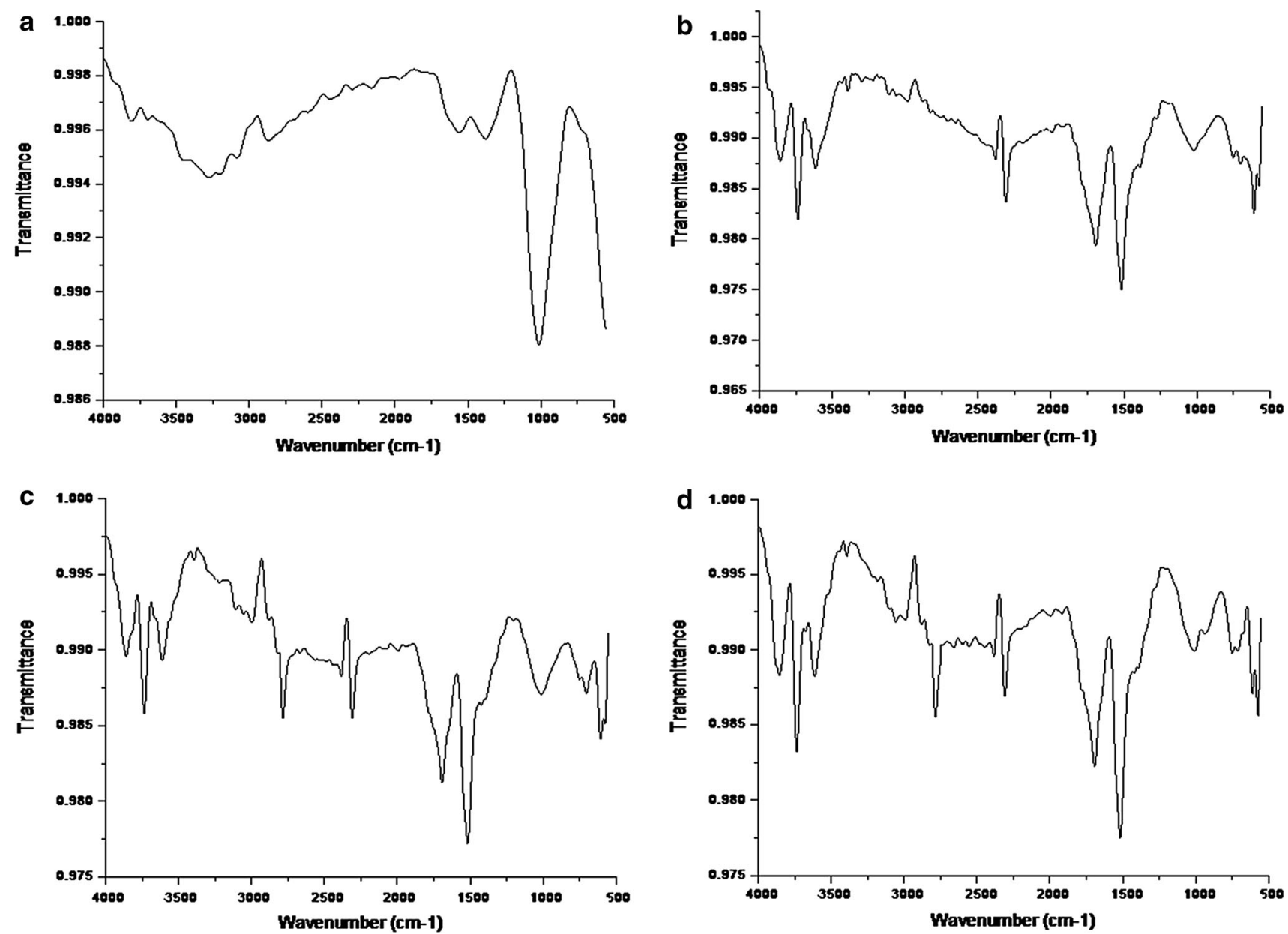

Fig. 1 FTIR spectrum of a chitosan, b SCC, $\mathbf{c}$ TBA-SCC, $\mathbf{d}$ TBA-SCC with adsorbed chromium 


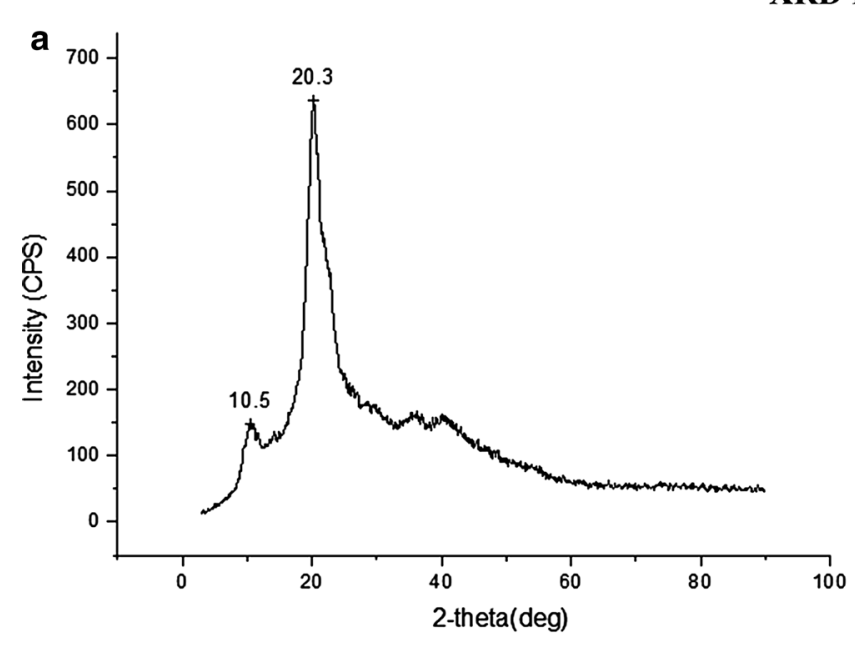

\section{XRD PATTERN}
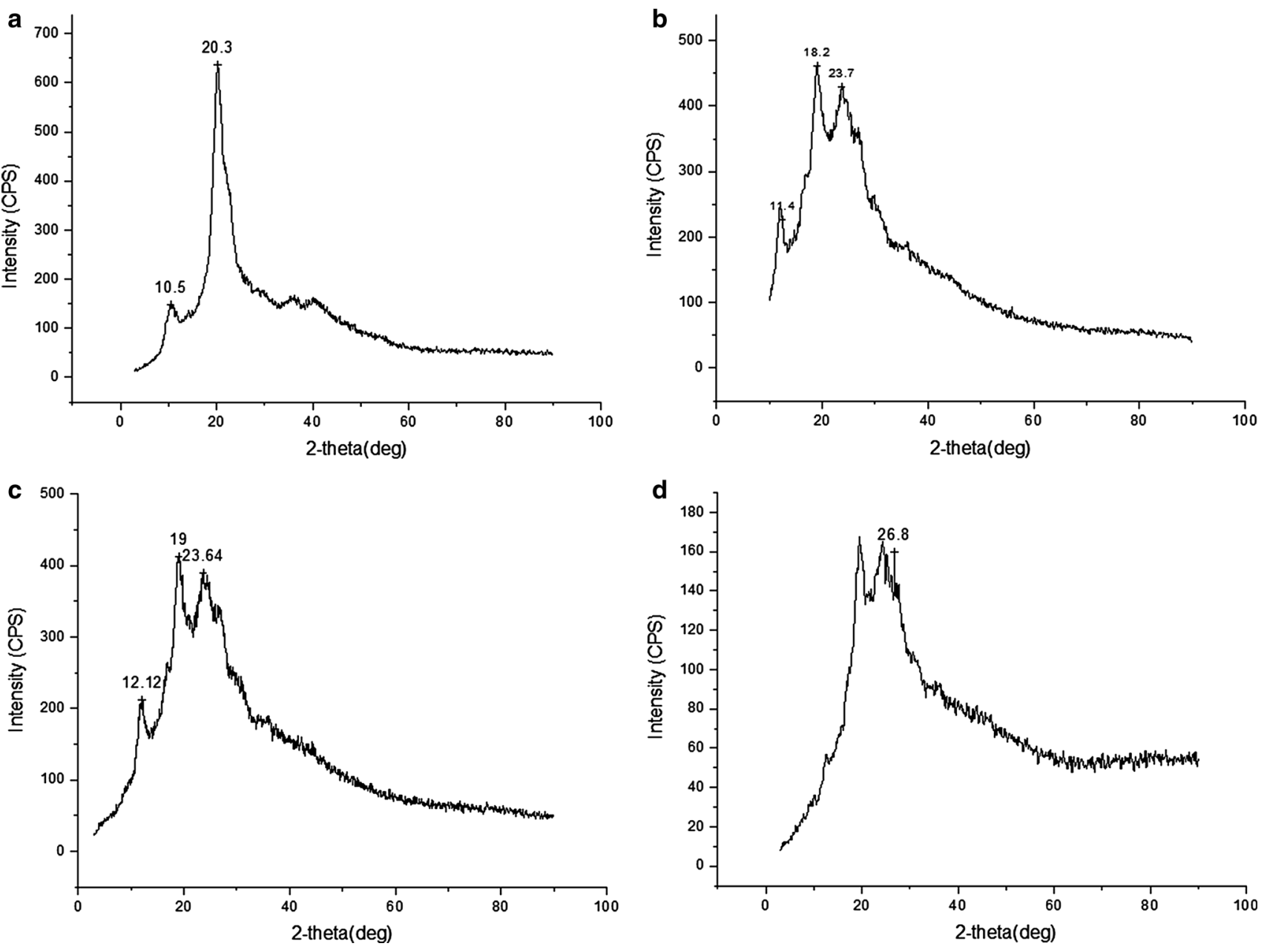

Fig. 2 XRD pattern a chitosan, b SCC, $\mathbf{c}$ TBA-SCC, d After adsorption of $\mathrm{Cr}(\mathrm{VI})$

\section{Morphology of adsorbent using SEM and EDX spectral analysis}

SEM micrographs (Fig. 3a) define the morphology of the adsorbent material. SCC exhibits regular and dense surfaces and became uniformly porous after impregnation with tetrabutyl ammonium bromide. SEM micrographs of the TBA-SCC with adsorbed $\mathrm{Cr}(\mathrm{VI})$ show glossy and bright spots indicating effective interaction of $\mathrm{Cr}(\mathrm{VI})$ with the adsorbent.

EDX spectra (Fig. 3b) of SCC, TBA-SCC and with adsorbed $\mathrm{Cr}(\mathrm{VI})$ confirmed the $\mathrm{Cr}(\mathrm{VI})$ adsorption. $\mathrm{In} \mathrm{Cr}(\mathrm{VI})$ adsorbed TBA-SCC characteristic peaks, $K_{\alpha}$ and $K_{\beta}$ of $\mathrm{Cr}(\mathrm{VI})$ along with the peaks of other elemental constituents such as sulphur, carbon, nitrogen, oxygen have been observed.

\section{Effect of contact time}

Effect of contact time on the adsorption of $\mathrm{Cr}(\mathrm{VI})$ concentration of $50 \mathrm{mg} \mathrm{L}^{-1}$ was studied by varying the contact time in the range $5-90 \mathrm{~min}$ at $298 \mathrm{~K}$. The rate of removal of $\mathrm{Cr}(\mathrm{VI})$ was found to be higher at the beginning while the equilibrium is reached in about $60 \mathrm{~min}$. Equilibrium was accomplished with adsorption of $99.6 \pm 0.1 \% \mathrm{Cr}(\mathrm{VI})$ in $60 \mathrm{~min}$ (Fig. 4a) which was fixed as contact time for further studies.

\% Removal of $\mathrm{Cr}(\mathrm{VI})$ can be calculated as

$\%$ Removal $=\frac{C_{0}-C_{\mathrm{e}}}{C_{0}} \times 100$

where $C_{0}$ and $C_{\mathrm{e}}$ refer to the initial and equilibrium liquidphase concentrations of $\mathrm{Cr}(\mathrm{VI})$ in $\mathrm{mg} \mathrm{L}^{-1}$.

\section{Effect of adsorbent amount}

The effect of TBA-SCC dose on adsorption efficiency was studied by varying its amounts from 50 to $400 \mathrm{mg}$ (Fig. 4b). Initially, due to greater interaction of dichromate ion and the adsorbent, \% removal of $\mathrm{Cr}(\mathrm{VI})$ increases rapidly. Beyond $200 \mathrm{mg}$ of TBA-SCC dose, unavailability 
Fig. 3 a SEM micrographs and b EDX spectra of chitosan and modified chitosan with $\mathrm{Cr}(\mathrm{VI})$ a
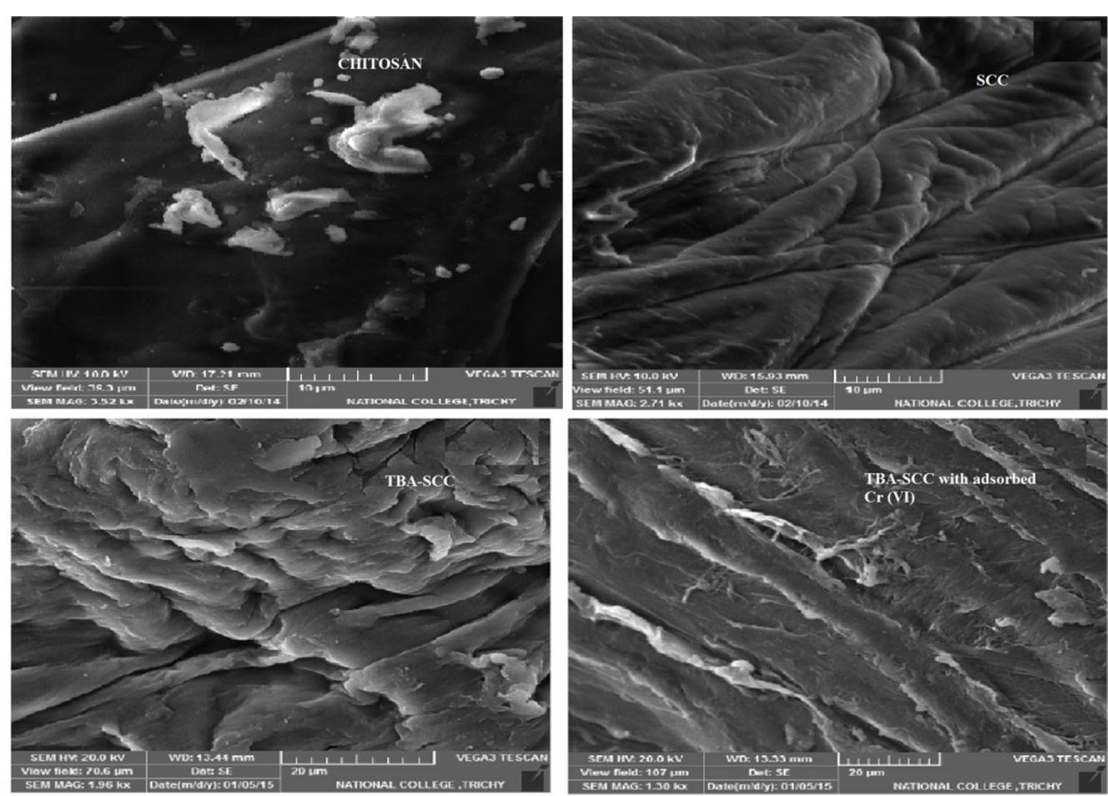

b
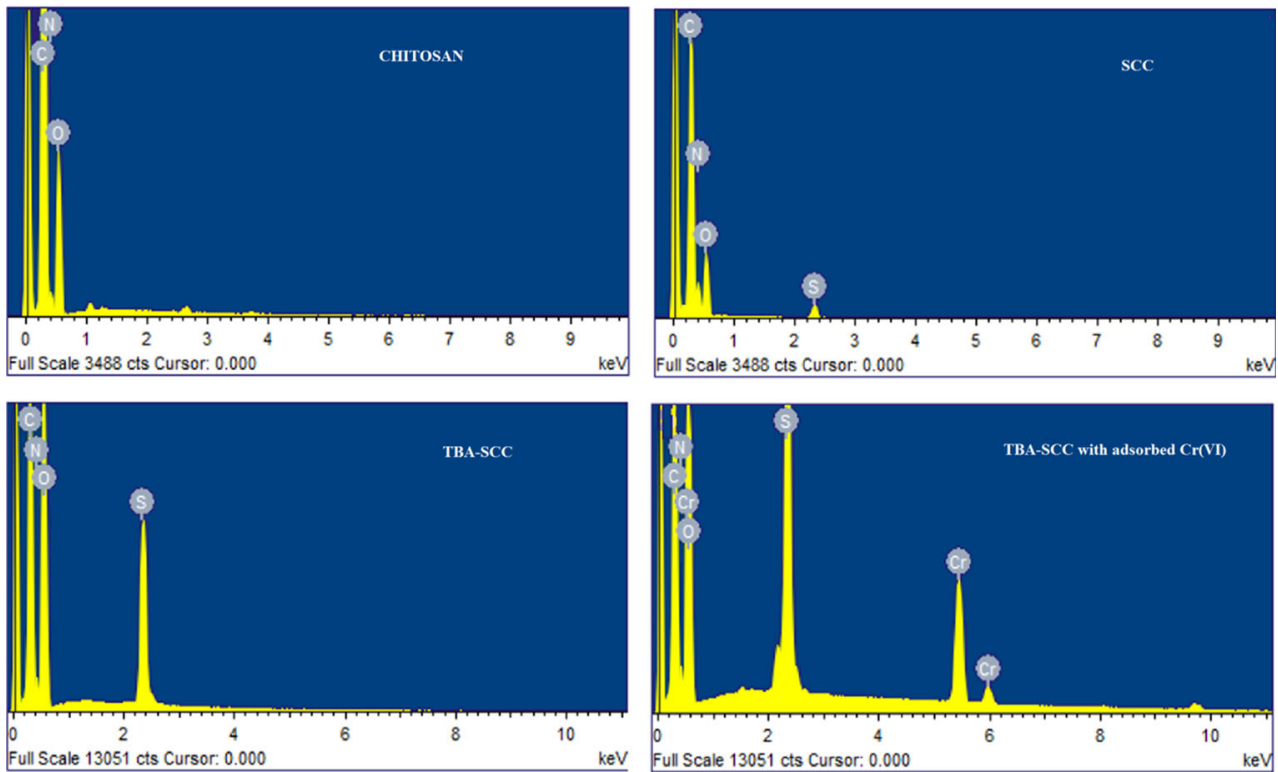

of adsorbate resulted in no observable rise in removal of $\mathrm{Cr}(\mathrm{VI})$. Hence, dose of $200 \mathrm{mg}$ was fixed for further adsorption studies.

\section{Effect of initial $\mathrm{Cr}(\mathrm{VI})$ concentration}

At different initial $\mathrm{Cr}(\mathrm{VI})$ concentrations (20-300 $\mathrm{mg} \mathrm{L}^{-1}$ ) with fixed contact time $(60 \mathrm{~min})$ and TBA-SCC dosage (200 mg), adsorption experiments were performed. Up to $50 \mathrm{mg} \mathrm{L}^{-1}$ of $\mathrm{Cr}(\mathrm{VI})$, the \% removal was found almost steady and then it started decreasing due to the saturation of adsorbent (Fig. 4c). Therefore, $50 \mathrm{mg} \mathrm{L}^{-1} \mathrm{Cr}$ (VI) solution was used for further adsorption studies.

\section{pH point of zero charge}

The $\mathrm{pH}$ at which the surface charge of the adsorbent became zero is known as $\mathrm{pH}$ point of zero charge $\left(\mathrm{pH}_{\mathrm{PZC}}\right)$. $\mathrm{pH}_{\mathrm{PZC}}$ of the adsorbent was determined by batch equilibration technique (Shekhawat et al. 2016). For this, $50 \mathrm{~mL}$ of $0.1 \mathrm{M} \mathrm{NaCl}$ solution was taken in a series of conical flasks and its initial $\mathrm{pH}$ was adjusted from 2.0 to 9.0 using dilute $\mathrm{H}_{2} \mathrm{SO}_{4}$ and $\mathrm{NaOH}$ solutions. These solutions were equilibrated with $100 \mathrm{mg}$ of TBA-SCC adsorbent for a period of $24 \mathrm{~h}$, and the final $\mathrm{pH}$ values of supernatant solutions were measured. The $\mathrm{pH}_{\mathrm{PZC}}$ of the TBA-SCC was evaluated from the plot of $\Delta \mathrm{pH}\left[\mathrm{pH}_{\text {initial }}-\mathrm{pH}_{\text {final }}\right]$ versus 

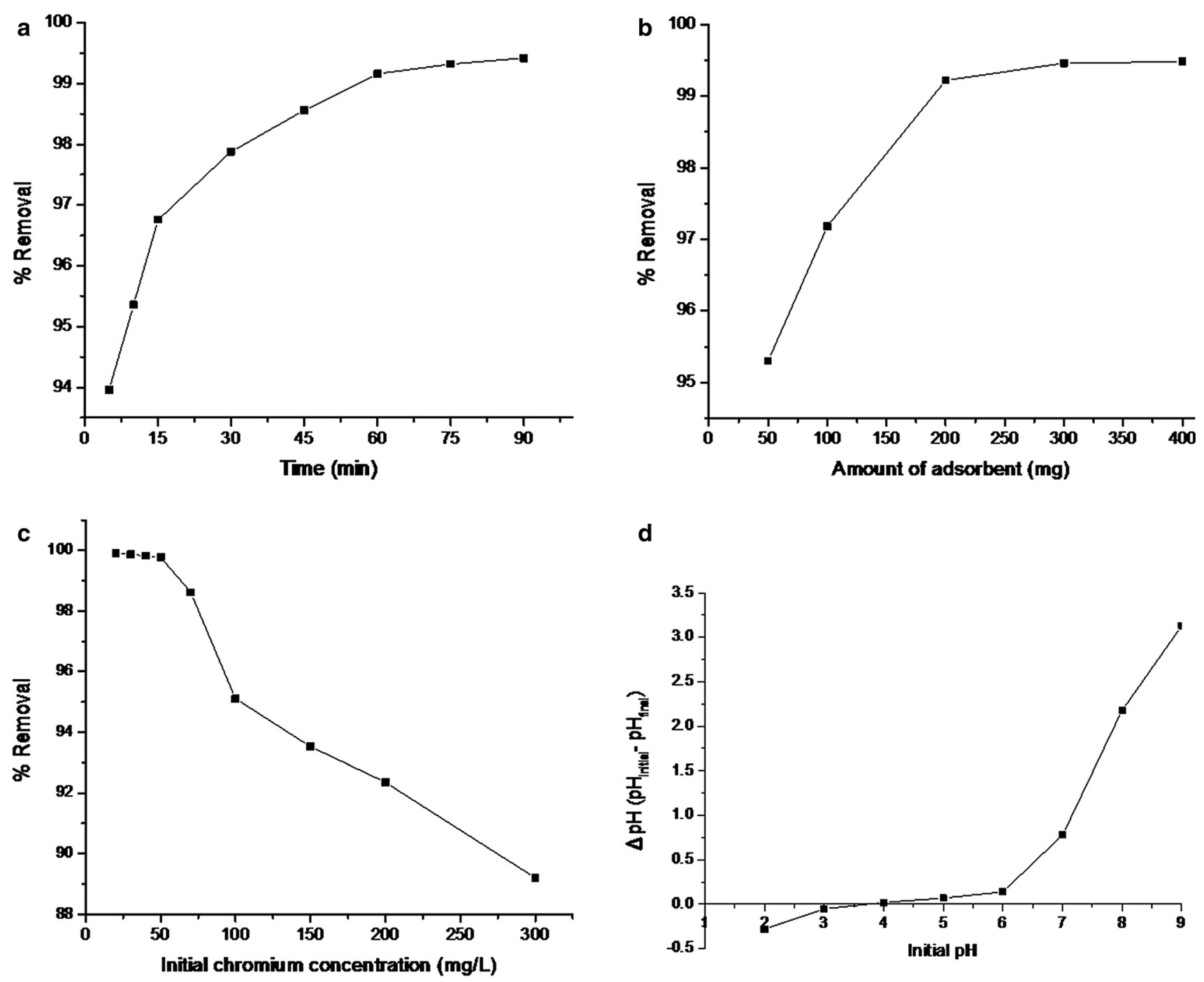

d
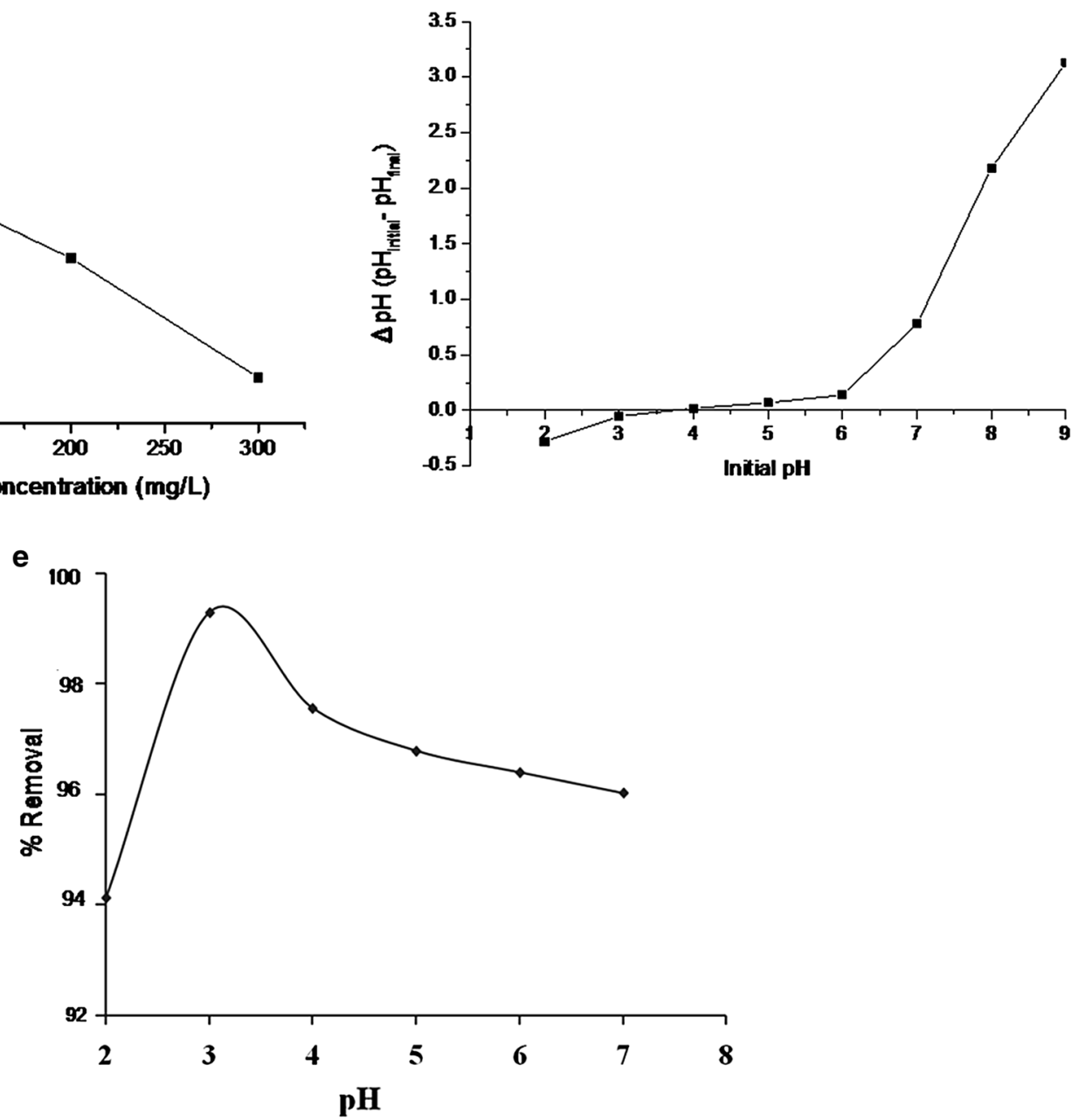

Fig. 4 Effect of $\mathbf{a}$ contact time, $\mathbf{b}$ adsorbent dose, $\mathbf{c}$ initial concentration, $\mathbf{d} \mathrm{pH}$ point of zero charge and $\mathbf{e}$ pH on adsorption efficiency 
$\mathrm{pH}_{\text {initial }}$. For TBA-SCC, the $\mathrm{pH}_{\mathrm{PZC}}$ was found to be 3.7 (Fig. 4d). It means that the adsorbent surface is positively charged below pH 3.7 and negatively charged above this $\mathrm{pH}$.

\section{Effect of pH}

Optimizing the $\mathrm{pH}$ is a significant parameter while assessing the adsorption capacity of an adsorbent. In aqueous medium, $\mathrm{Cr}(\mathrm{VI})$ mainly exists in different forms such as hydrogen chromate $\left(\mathrm{HCrO}_{4}^{-}\right)$, dichromate $\left(\mathrm{Cr}_{2} \mathrm{O}_{7}{ }^{2-}\right)$ and chromate $\left(\mathrm{CrO}_{4}{ }^{2-}\right)$. The equilibrium exists between these anions depending on pH (Zhu et al. 2009) as follows:

$$
\begin{aligned}
& \mathrm{H}_{2} \mathrm{CrO}_{4} \rightleftharpoons \mathrm{H}^{+}+\mathrm{HCrO}_{4}^{-} \\
& \mathrm{HCrO}_{4}^{-} \rightleftharpoons \mathrm{H}^{+}+\mathrm{CrO}_{4}^{2-} \\
& 2 \mathrm{HCrO}_{4}^{-} \rightleftharpoons \mathrm{Cr}_{2} \mathrm{O}_{7}^{2-}+\mathrm{H}_{2} \mathrm{O}
\end{aligned}
$$

Also, the speciation of adsorbate and surface charge of the adsorbent can be related to $\mathrm{pH}$. The $\mathrm{pH}$ of the solution was varied from 2.0 to 7.0 at constant initial concentration of $50 \mathrm{mg} \mathrm{L}^{-1}$ of $\mathrm{Cr}(\mathrm{VI})$, contact time of $60 \mathrm{~min}$ and $298 \mathrm{~K}$ temperature. It was found that the $\%$ removal was maximum at $\mathrm{pH} 3.0 \pm 0.1$ (Fig. 4e) which favours the formation of dichromate anion and also protonation of the surface nitrogen-containing group. Dichromate anion shows ion pair interaction with $\mathrm{N}^{+}\left(\mathrm{C}_{4} \mathrm{H}_{9}\right)_{4}$ of TBA-SCC and also gets exchanged with crosslinked sulphate ions of the adsorbent. At this $\mathrm{pH}$ condition, the surface of adsorbent is positively charged (below $\mathrm{pH}_{\mathrm{PZC}}$ ) that favours electrostatic interaction with dichromate ion.

\section{Adsorption isotherms}

Various adsorption isotherm models such as Langmuir, Freundlich and Dubinin-Radushkevich (D-R) were studied quantitatively. The adsorption studies were carried out by equilibrating $50 \mathrm{~mL}$ of varying initial $\mathrm{Cr}(\mathrm{VI})$ concentrations (100-800 $\mathrm{mg} \mathrm{L}^{-1}$ ) at $\mathrm{pH} 3.0$ with $200 \mathrm{mg}$ of TBA$\mathrm{SCC}$ at $298 \mathrm{~K}$ for $60 \mathrm{~min}$.

The purpose of Langmuir isotherm model study is to understand the monolayer adsorption on homogeneous surface and to calculate the maximum adsorption capacity of adsorbent (Langmuir 1918). It relates the maximum adsorption capacity $\left(q_{0}\right)$ and the Langmuir constant related to affinity of binding sites $(b)$ in linearized Langmuir equation:

$\frac{C_{\mathrm{e}}}{q_{\mathrm{e}}}=\frac{1}{q_{0} b}+\frac{C_{\mathrm{e}}}{q_{0}}$

The maximum adsorption capacity $q_{0}$ and the constant $\mathrm{b}$ were obtained from the slope and intercept of the plot of
$C_{\mathrm{e}} / q_{\mathrm{e}}$ against $C_{\mathrm{e}}$ (Fig. 5a). A high adsorption capacity of $225.9 \mathrm{mg} \mathrm{g}^{-1}$ accounts for excellent adsorption behaviour of TBA-SCC adsorbent for $\mathrm{Cr}(\mathrm{VI})$. A separation factor $R_{\mathrm{L}}$ that relates to the favourable nature of adsorption is given by the following equation:

$R_{\mathrm{L}}=\frac{1}{1+b C_{o}}$

$R_{\mathrm{L}}$ value less than unity (Table 1 ) indicating effective interaction (Crini et al. 2007) between the TBA-SCC and $\mathrm{Cr}(\mathrm{VI})$ at the optimized experimental conditions.

Inequivalent adsorbent sites lead to surface heterogeneity during adsorption, which has been explained by Freundlich isotherm model (Freundlich 1906). $k_{\mathrm{F}}$ refers to adsorption capacity, and $n$ indicates the adsorption intensity with the linearized expression given as

$\log q_{\mathrm{e}}=\log k_{\mathrm{F}}+\frac{1}{n} \log C_{\mathrm{e}}$

The logarithmic plot of $q_{\mathrm{e}}$ against $C_{\mathrm{e}}$ gives the constants $k_{\mathrm{F}}$ and $\mathrm{n}$ (Fig. 5b). The smaller value of $1 / n 0.614(0.1<1 /$ $n<1.0$ ) (Table 1) signifies an active interaction between TBA-SCC and Cr(VI) (Kumar and Rajesh 2013).

Dubinin-Radushkevich isotherm is commonly used to predict the type of adsorption mechanism and the interaction between the adsorbate and adsorbent (Dubinin and Radushkevich 1947). The D-R isotherm parameters $\beta$ a constant related to adsorption energy and $\varepsilon$, Polyani potential is expressed as

$\ln q_{\mathrm{e}}=\ln q_{\mathrm{m}}-\beta \varepsilon^{2}$

where $q_{\mathrm{m}}\left(\mathrm{mg} \mathrm{g}^{-1}\right)$ is the adsorption capacity. The intercept and slope in plot of $\ln q_{\mathrm{e}}$ verses $\varepsilon^{2}$ give the values of $q_{\mathrm{m}}$ and $\beta$, respectively (Fig. 5c). The value of $\varepsilon$ was calculated using following equation

$\varepsilon=R T \ln \left(1+\frac{1}{C_{\mathrm{e}}}\right)$

where $R\left(8.314 \mathrm{~J} \mathrm{~mol}^{-1} \mathrm{~K}^{-1}\right)$ is a gas constant and $T(\mathrm{~K})$ is absolute temperature. The mean free adsorption energy was calculated by the following equation:

$E=-\left(\frac{1}{(2 \beta)^{0.5}}\right)$

In the present work, the value of $E$ was found to be $-6.47 \mathrm{~kJ} \mathrm{~mol}^{-1}$. This value reflects both chemisorption and physisorption. Value of $\beta, \mathrm{E}$ and $q_{\mathrm{m}}$ was depicted in Table 1.

The values of regression coefficient (Table 1) and the plot of experimental $q_{\mathrm{e}}$ along with $q_{\mathrm{e}}$ values of all the isotherms against $C_{\mathrm{e}}$ (Fig. 5d) implie that the Freundlich isotherm model has good agreement with experimental $q_{\mathrm{e}}$ 
Fig. 5 Adsorption isothems: a Langmuir, b Freundlich, c D$\mathrm{R}, \mathrm{d}$ comparison of experimental $q_{\mathrm{e}}$ with other isotherms
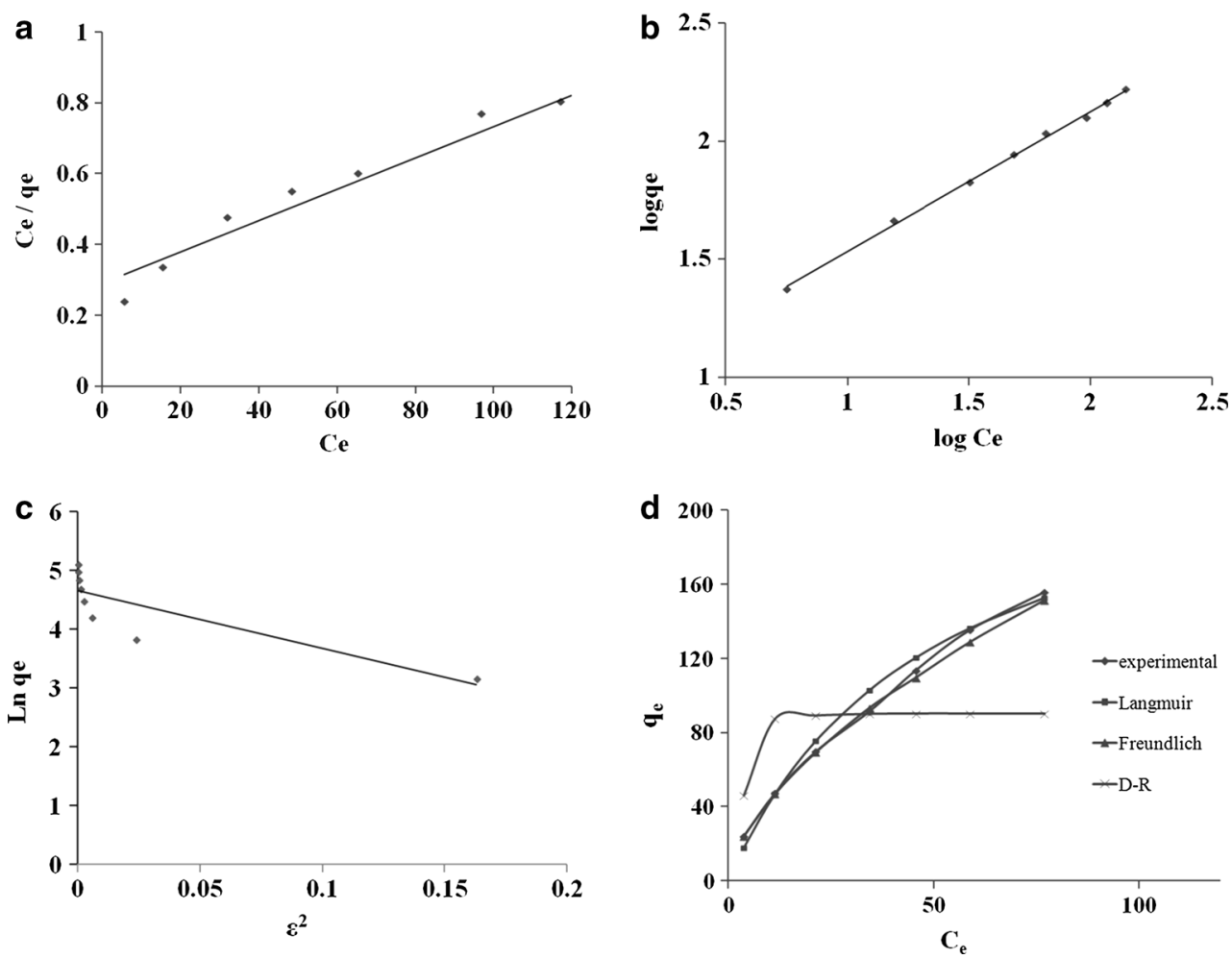

Table 1 Isotherm parameters acquired from various models

\begin{tabular}{llll}
\hline S1. no. & Isotherms & Parameters & Values \\
\hline 1. & Langmuir & $q_{0}\left(\mathrm{mg} \mathrm{g}^{-1}\right)$ & 225.9 \\
& & $\mathrm{~b}\left(\mathrm{~L} \mathrm{mg}^{-1}\right)$ & 0.015 \\
& & $R_{\mathrm{L}}$ & 0.567 \\
& & $r^{2}$ & 0.950 \\
2. & Freundlich & $K_{\mathrm{F}}\left(\mathrm{mg}^{1-1 / n} \mathrm{~g}^{-1} \mathrm{~L}^{-1}\right)$ & 10.62 \\
& & $n$ & 1.679 \\
& & $r^{2}$ & 0.997 \\
3. & Dubinin Radushkevich & $q_{\mathrm{m}}\left(\mathrm{mg} \mathrm{g}^{-1}\right)$ & 109.69 \\
& & $\beta\left(\mathrm{mol}^{2} \mathrm{~kJ}^{-2}\right)$ & $4.82 \mathrm{E}-6$ \\
& & $\mathrm{E}\left(\mathrm{kJ} \mathrm{mol}^{-1}\right)$ & -6.47 \\
& $r^{2}$ & 0.704 \\
\hline
\end{tabular}

with highest value for regression coefficient. Thus, Freundlich isotherm was the best fit model for adsorption of $\mathrm{Cr}(\mathrm{VI})$ by TBA-SCC which assumes heterogeneous multilayer adsorption.

\section{Kinetics of adsorption}

The amount of metal ion adsorbed by the adsorbent depends on the contact time, and thus, kinetics of adsorption of $\mathrm{Cr}(\mathrm{VI})$ on to the TBA-SCC was explained through pseudo-first-order and pseudo-second-order kinetic models. The studies were carried out using $50 \mathrm{~mL}, 50 \mathrm{mg} \mathrm{L}^{-1}$
$\mathrm{Cr}$ (VI) solution at $\mathrm{pH}$ 3.0. It was equilibrated with $200 \mathrm{mg}$ of TBA-SCC at $298 \mathrm{~K}$ for different time intervals (5-90 min).

The pseudo-first-order kinetics (Lagergren 1898) is given by the equation

$\log \left(q_{\mathrm{e}}-q_{t}\right)=\log q_{\mathrm{e}}-\frac{k_{1} t}{2.303}$

where $q_{\mathrm{e}}$ and $q_{t}$ refer to the amounts of $\mathrm{Cr}(\mathrm{VI})$ adsorbed at equilibrium and at time $t$ with the first-order rate constant $k_{1}$. The plot of $\log \left(q_{\mathrm{e}}-q_{t}\right)$ against $t$ gives pseudo-firstorder rate constant with regression coefficient 0.766 (Fig. 6a).

The pseudo-second-order equation (Ho 2006) is given as

$\frac{t}{q_{t}}=\frac{1}{k_{2} q_{\mathrm{e}}^{2}}+\frac{t}{q_{\mathrm{e}}}$

where $k_{2}$ is the pseudo-second-order rate constant in $\mathrm{g} \mathrm{mg}^{-1} \min ^{-1}$. The plot of $\log t / q_{t}$ against $t$ (Fig. 6b) gives pseudo-second-order rate constant. Regression coefficient of 0.999 for pseudo-second-order rate kinetics offers a best fit model to describe the adsorption of $\mathrm{Cr}(\mathrm{VI})$ on to TBASCC.

During adsorption whether intraparticle diffusion is the rate-determining step can be confirmed by Weber-Morris model (Weber and Morris 1963). According to this model, $q_{t}$ and $t^{1 / 2}$ of adsorption process are related as:

$q_{t}=k_{\mathrm{int}} \cdot t^{1 / 2}+C$ 
Fig. 6 Kinetic and thermodynamic studies: a pseudo-first-order kinetics, b pseudo-second-order kinetics, c intraparticle diffusion, $\mathbf{d}$ van't Hoff plot
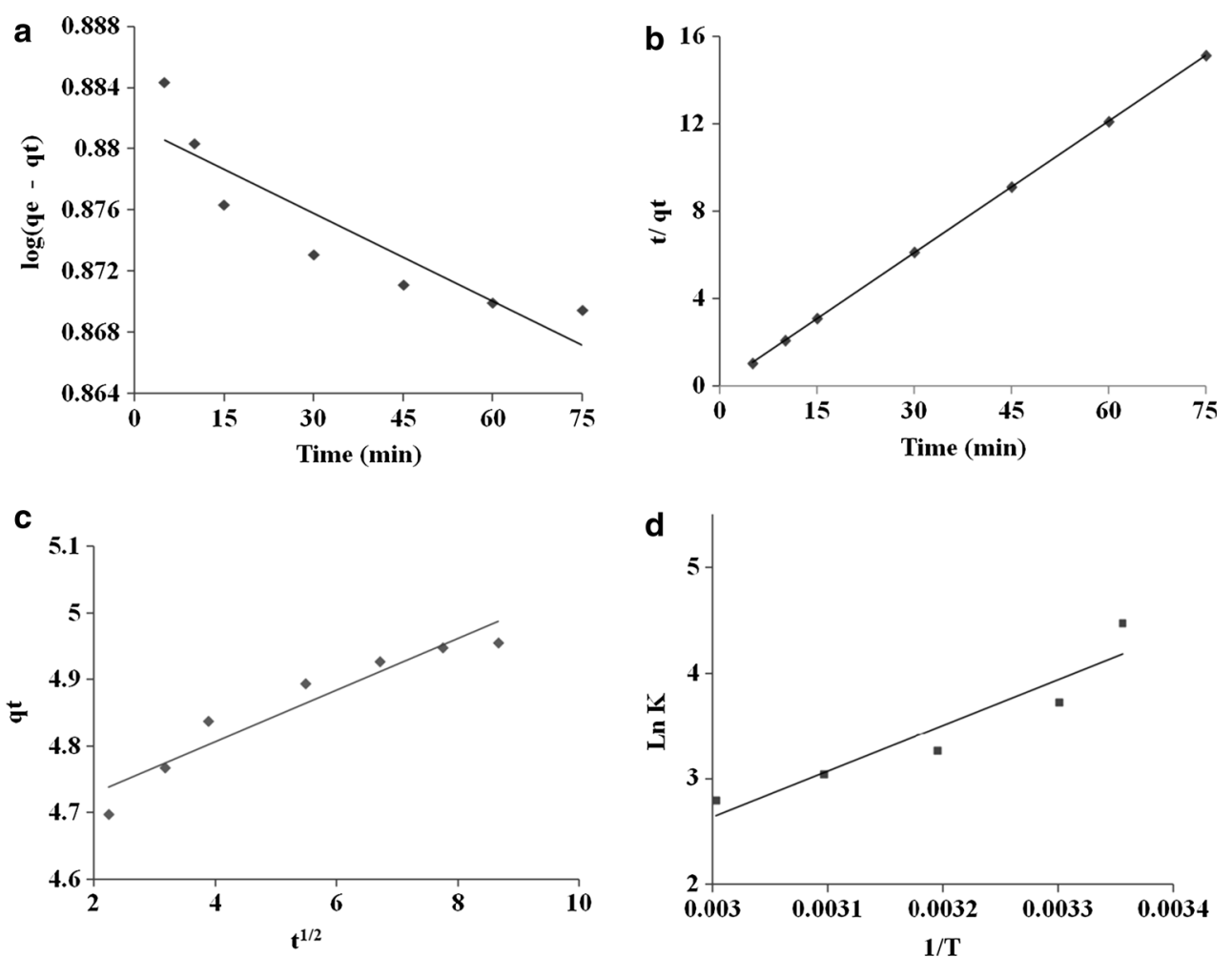

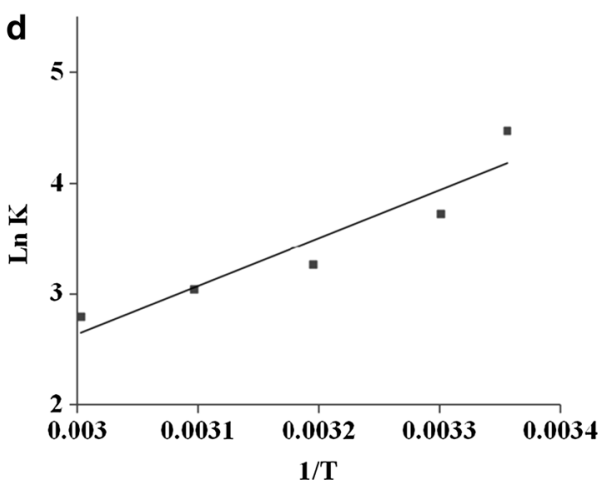

If the plot of $q_{t}$ verses $t^{1 / 2}$ (Fig. 6c) passes through origin and is linear, then intraparticle diffusion is the only ratelimiting step. The slope gives the intraparticle rate constant $k_{\text {int }}$ (Table 2), and nonzero intercept showed that diffusion is not the only rate-limiting step. Rate of adsorption of $\mathrm{Cr}$ (VI) may be influenced by external mass transfer of $\mathrm{Cr}$ (VI) from solution phase to solid phase, pore diffusion and at interior sites of the adsorbent. Thus, the adsorption of $\mathrm{Cr}$ (VI) by TBA-SCC was controlled by boundary layer as well as diffusion process (Bulut et al. 2008).

\section{Thermodynamics of adsorption}

Effect of temperature on adsorption of $\mathrm{Cr}(\mathrm{VI})$ by TBASCC was studied in order to obtain relevant thermodynamic parameters at 298, 303, 308, 318 and $328 \mathrm{~K}$. These parameters describe the spontaneous nature of adsorption. The free energy change of adsorption $\left(\Delta G^{\circ}\right)$ is given by

$\Delta G^{0}=-R T \ln K$

van't Hoff equation (Donia et al. 2006) which relates entropy $\left(\Delta S^{\circ}\right)$ and enthalpy $\left(\Delta H^{\circ}\right)$ changes is given by

$\ln K=\frac{\Delta S^{0}}{R}-\frac{\Delta H^{0}}{R T}$

where $R$ is the gas constant $\left(8.314 \mathrm{~J} \mathrm{~mol}^{-1} \mathrm{~K}^{-1}\right)$. The value of equilibrium constant $K$ has been evaluated from the ratio of concentration of $\mathrm{Cr}(\mathrm{VI})$ adsorbed to that in the solution phase. The values of $\Delta H$ and $\Delta S$ (Table 2) were obtained from slope and intercept of the plot of $\ln K$ against $1 / T$ (Fig. 6d), respectively. The negative free energy change indicates the spontaneous nature, negative enthalpy change indicates the exothermic nature of adsorption process, while negative entropy change indicates the decrease in randomness of $\mathrm{Cr}(\mathrm{VI})$ as it passes from solution to adsorbed state.

\section{Column studies}

Column adsorption studies were performed by using glass column of $30.0 \mathrm{~cm}$ length, and $1.0 \mathrm{~cm}$ inner diameter was used to understand the applicability of adsorbent for larger sample volumes. Column was packed with $1.0 \mathrm{~g}$ of adsorbent to the height of $6.0 \mathrm{~cm}$. $1500 \mathrm{~mL}$ of $200 \mathrm{mg} \mathrm{L}^{-1} \mathrm{Cr}(\mathrm{VI})$ solution was passed through the column at the flow rate of $5 \mathrm{~mL} \mathrm{~min}{ }^{-1}$. Concentration of $\mathrm{Cr}(\mathrm{VI})$ in solution phase was analysed spectrophotometrically to quantify the column efficiency. Adsorption of $\mathrm{Cr}(\mathrm{VI})$ was found to be almost $100 \%$ up to $900 \mathrm{~mL}$ of $200 \mathrm{mg} \mathrm{L}^{-1} \mathrm{Cr}$ (VI) (Fig. 7) solution. The identical results were obtained in three replicates. These results clearly indicate that larger sample volumes containing $\mathrm{Cr}(\mathrm{VI})$ can be effectively treated using column method compared to batch extraction. 
Table 2 Kinetics and thermodynamic parameters

\begin{tabular}{|c|c|c|c|c|c|}
\hline \multicolumn{6}{|c|}{ Kinetics parameters } \\
\hline \multicolumn{2}{|c|}{ Pseudo-first-order kinetics } & \multicolumn{2}{|c|}{ Pseudo-second-order kinetics } & \multicolumn{2}{|l|}{ Intraparticle diffusion } \\
\hline$k_{1}\left(\min ^{-1}\right)$ & Regression coefficient & $k_{2}\left(\mathrm{~g} \mathrm{mg}^{-1} \mathrm{~min}^{-1}\right)$ & Regression coefficient & $k_{\text {int }}\left(\mathrm{mg} \mathrm{g}^{-1} \min ^{-1 / 2}\right)$ & Regression coefficient \\
\hline 0.0002 & 0.813 & 0.095 & 0.999 & 0.038 & 0.911 \\
\hline \multicolumn{6}{|c|}{ Thermodynamic parameters } \\
\hline \multicolumn{2}{|l|}{ Temperature } & $\Delta G\left(\mathrm{~kJ} \mathrm{~mol}^{-1}\right)$ & \multicolumn{2}{|c|}{$\Delta H\left(\mathrm{~kJ} \mathrm{~mol}^{-1}\right)$} & $\Delta S\left(\mathrm{~kJ} \mathrm{~mol}^{-1} \mathrm{~K}^{-1}\right)$ \\
\hline \multicolumn{2}{|l|}{$298 \mathrm{~K}$} & -11.10 & \multicolumn{2}{|l|}{-36.041} & -0.0862 \\
\hline \multicolumn{2}{|l|}{$303 \mathrm{~K}$} & -9.39 & & & \\
\hline \multicolumn{2}{|l|}{$308 \mathrm{~K}$} & -8.51 & & & \\
\hline \multicolumn{2}{|l|}{$318 \mathrm{~K}$} & -8.16 & & & \\
\hline \multicolumn{2}{|l|}{$328 \mathrm{~K}$} & -7.37 & & & \\
\hline
\end{tabular}

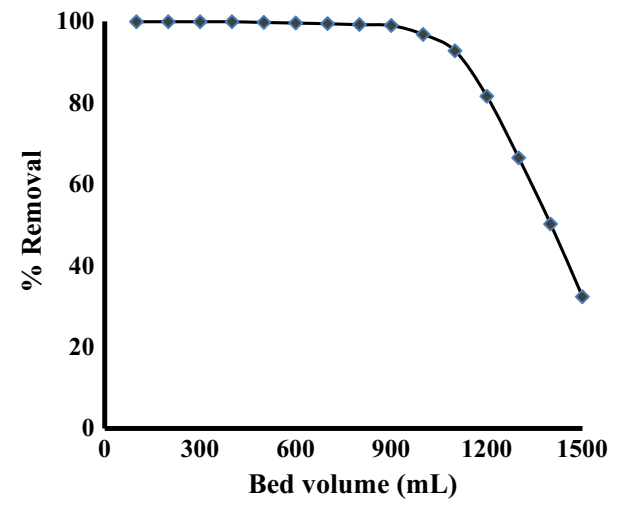

Fig. 7 Effect of bed volume on column efficiency

\section{Effect of assorted ions}

The real effluent wastewater contains varied anions and cations which may compete for the accessible active sites on the TBA-SCC surface. Hence, it is important to study the effect of individual ion on selectivity towards $\mathrm{Cr}(\mathrm{VI})$. Various anions such as $\mathrm{SO}_{4}{ }^{2-}, \mathrm{Cl}^{-}, \mathrm{NO}_{3}{ }^{-}, \mathrm{PO}_{4}{ }^{3-}$ and cations such as $\mathrm{Cu}^{2+}, \mathrm{Ni}^{2+}, \mathrm{Co}^{2+}, \mathrm{Zn}^{2+}, \mathrm{Fe}^{2+}$ and $\mathrm{Fe}^{3+}$ present in a real wastewater were tested for their effect on adsorption of $\mathrm{Cr}(\mathrm{VI})$ by TBA-SCC. For this, adsorption studies were carried out using $50 \mathrm{~mL}$ of $1 \mathrm{mM} \mathrm{Cr}(\mathrm{VI})$ solution in the presence of equimolar interfering ions under optimized conditions. From Fig. 8a, b, it is clear that the $\mathrm{Cl}^{-}$and $\mathrm{Fe}$ (total) interfere to the greatest extent among these ions.

\section{Regeneration and reusability of adsorbent}

The regeneration of adsorbent is important from a greener point. Reagents such as sodium hydroxide, sodium carbonate and sulphuric acid were examined for desorption studies. In the present study, the regenerated TBA-SCC is effectively used for ten adsorption-desorption cycles with no change in adsorption capacity compared to freshly prepared TBA-SCC (Fig. 8c). The best results were obtained with $2 \%(w / v) \mathrm{NaOH}$ solution (Fig. 8d). $2 \mathrm{~g}$ of TBA-SCC with adsorbed $\mathrm{Cr}(\mathrm{VI})$ was taken in round bottom flask, to it $50 \mathrm{~mL}$ of $2 \% \mathrm{NaOH}$ solution was added and boiled for $30 \mathrm{~min}$. The reaction mixture was cooled, filtered and then washed with distilled water to regenerate chitosan (checked by IR characterization of the residue). It clearly indicates that the crosslinking as well as impregnation breaks down at high $\mathrm{pH}$ of $\mathrm{NaOH}$ solution. It could be further modified to TBA-SCC and the regenerated compound was found to have the same adsorption efficiency (Fig. 8e).

\section{Applicability to synthetic effluent}

In order to confirm the applicability of TBA-SCC for removal of $\mathrm{Cr}(\mathrm{VI})$, three different synthetic effluents were prepared having similar composition to that of real effluents and adsorption efficiency was determined (Rajesh et al. 2011). The cations such as $\mathrm{Ni}^{2+}, \mathrm{Cu}^{2+}, \mathrm{Co}^{2+}$, $\mathrm{Zn}^{2+}, \mathrm{Fe}^{2+}, \mathrm{Fe}^{3+}$ and anions as $\mathrm{Cl}^{-}, \mathrm{SO}_{4}{ }^{2-}, \mathrm{NO}_{3}{ }^{-}$, $\mathrm{PO}_{4}{ }^{3-}$ present in effluents affect the adsorption efficiency. These ions may interfere and alters the adsorption capacity. The results have been depicted in Table 3 . More than $94 \%$ removal of $\mathrm{Cr}(\mathrm{VI})$ was observed in single batch extraction which may further be improved using multiple extractions. The used adsorbent was analysed by EDX. The spectrum (Fig. 9) clearly shows the presence of chloride ions indicating their involvement in the adsorption process. 

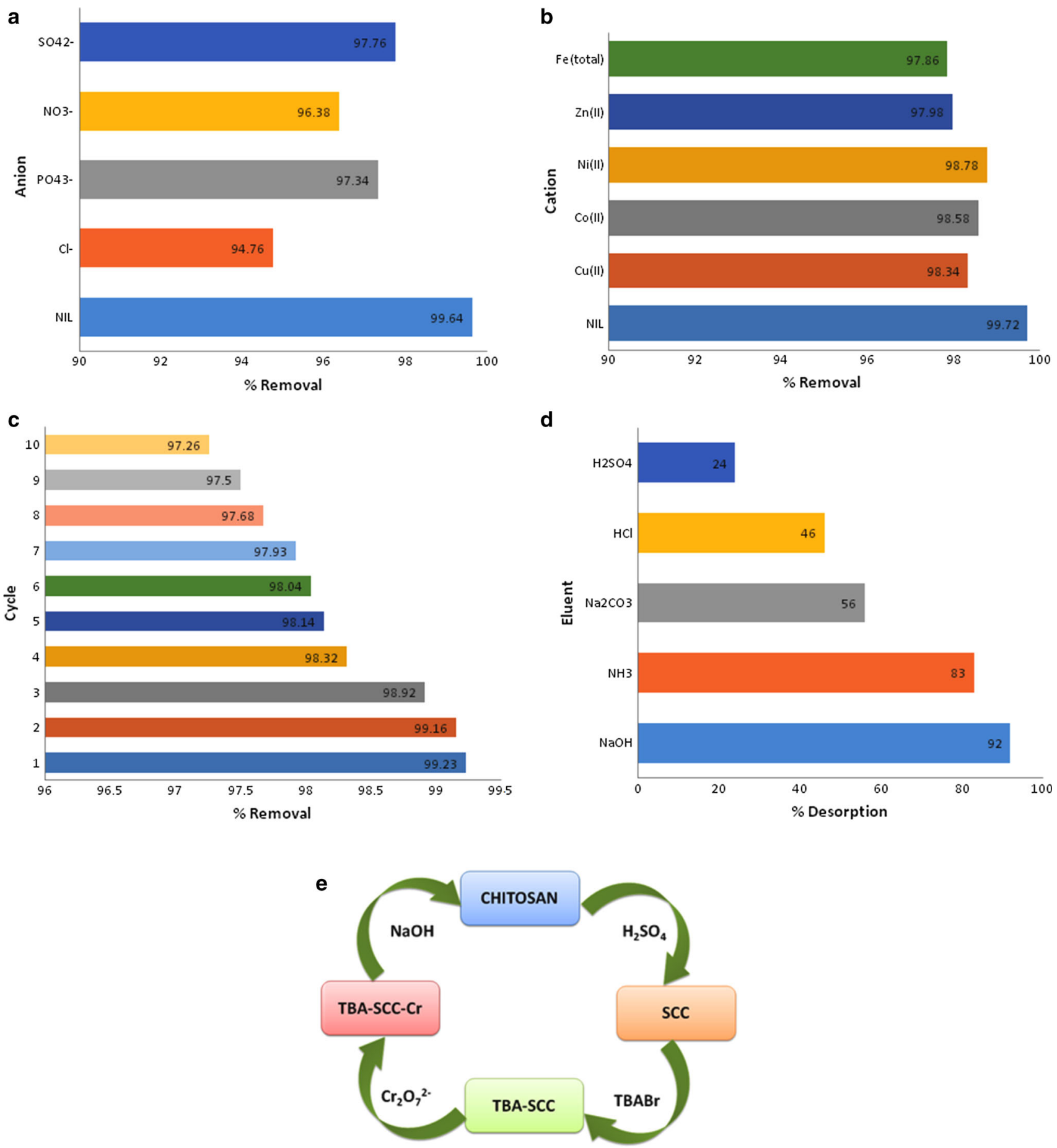

Fig. 8 Effect of a anion, b cation on \% removal of $\mathrm{Cr}(\mathrm{VI})$, $\mathbf{c}$ regeneration cycles, $\mathbf{d}$ desorption studies, e mechanism of regeneration

\section{Mechanism of adsorption of $\mathrm{Cr}(\mathrm{VI})$ by TBA-SCC}

In TBA-SCC, sulphate ions and $\mathrm{N}^{+}\left(\mathrm{C}_{4} \mathrm{H}_{9}\right)_{4}$ are juxtaposed in such a manner to facilitate the effective adsorption of dichromate ions. In the host-guest complexation phenomena, the resulting binding energies were due to the electrostatic and van der Waals interactions (Houk et al. 2003). In present work, Cr(VI) adsorption shows concurrent behaviour involves ion pair interactions with $\mathrm{N}^{+}\left(\mathrm{C}_{4} \mathrm{H}_{9}\right)_{4}$ and ion exchange 
Table 3 Application of TBA-SCC to synthetic effluents

\begin{tabular}{lll}
\hline Synthetic effluent & Concentration of ions $\left(\mathrm{mg} \mathrm{L}^{-1}\right)$ & \% Removal of chromium \\
\hline 1 & $\mathrm{Cl}^{-}(750), \mathrm{SO}_{4}{ }^{2-}(859), \mathrm{NO}_{3}{ }^{-}(100), \mathrm{Mn}^{2+}(750), \mathrm{Fe}^{2+}(500)$, total $\mathrm{Cr}(200)$ & $96.2 \pm 0.2$ \\
2 & $\mathrm{Cl}^{-}(605), \mathrm{SO}_{4}{ }^{2-}(1375), \mathrm{NO}_{3}{ }^{-}(500), \mathrm{Zn}^{2+}(500), \mathrm{Fe}^{2+}(350), \mathrm{Ni}^{2+}(500)$, total $\mathrm{Cr}(200)$ & $97.5 \pm 0.2$ \\
3 & $\mathrm{Cl}^{-}(953), \mathrm{SO}_{4}{ }^{2-}(1041), \mathrm{NO}_{3}{ }^{-}(700), \mathrm{Fe}^{2+}(100), \mathrm{Fe}^{3+}(500), \mathrm{Ni}^{2+}(500)$, total $\mathrm{Cr}(200)$ & $94.1 \pm 0.3$ \\
\hline
\end{tabular}

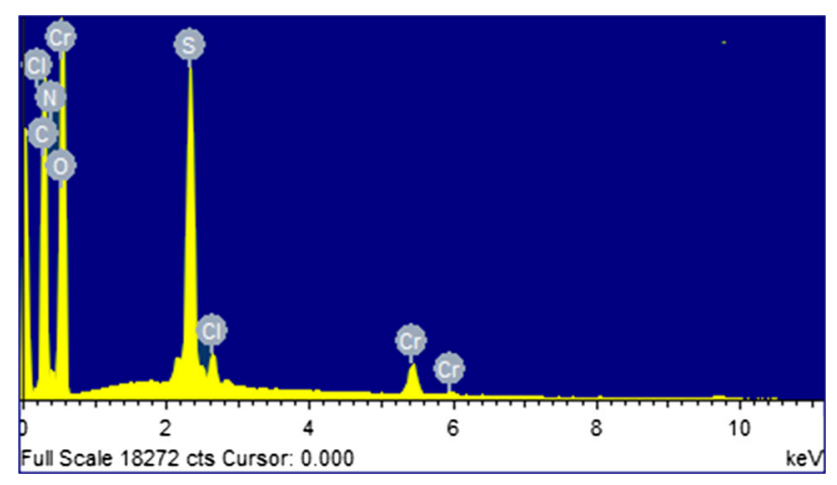

Fig. 9 EDX spectrum of adsorbent after adsorption of $\mathrm{Cr}(\mathrm{VI})$ in synthetic effluent

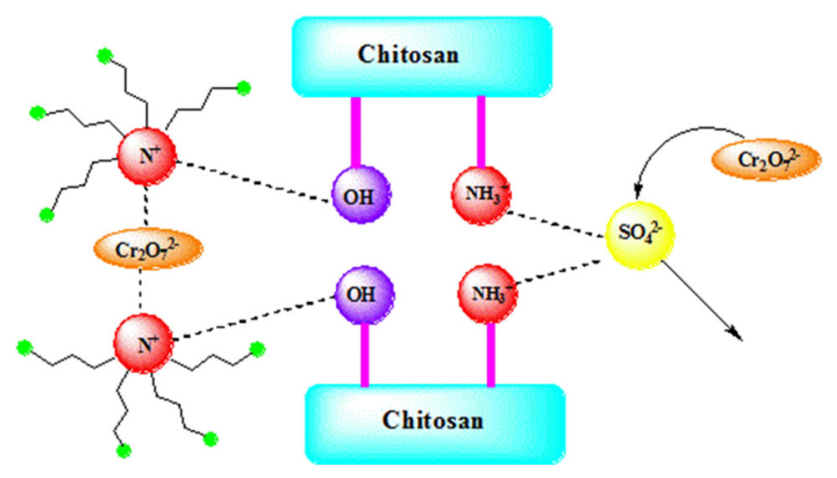

Fig. 10 Mechanism of adsorption phenomena with sulphate ions of TBA-SCC (Fig. 10). Ion exchange phenomena were predicted by the sulphate ions detection in the remaining aqueous medium after the adsorption of $\mathrm{Cr}(\mathrm{VI})$.

\section{Comparison with other related adsorbents}

The adsorption capacity is a yardstick to assess an adsorbent. The adsorption capacity of TBA-SCC is higher than some of the other reported biopolymer adsorbents (Table 4).

\section{Conclusion}

Generally impregnation of an adsorbent will take $4 \mathrm{~h}$ with simple conventional method (Kumar et al. 2014a, b). Present work has demonstrated that the impregnation could be performed in 2 min by using domestic microwave and the resulting adsorbent has high adsorption efficiency. The interaction between the SCC and tetrabutyl ammonium bromide enhances the potential application of adsorbent for the effective adsorption of $\mathrm{Cr}(\mathrm{VI})$. Experimental data showed adsorption process follows pseudo-second order kinetics. The TBA-SCC adsorbent has shown estimable adsorption capacity of $225.9 \mathrm{mg} \mathrm{g}^{-1}$ for hexavalent chromium. This can be attributed to the co-operation of electrostatic interaction and ion exchange phenomena at quaternary ammonium and sulphate ions sites of adsorbent,

Table 4 Comparison of adsorption capacity

\begin{tabular}{lllll}
\hline S1. no. & Adsorbents & $\begin{array}{l}\text { Degree of } \\
\text { deacetylation }(\%)\end{array}$ & $\begin{array}{l}\text { Adsorption capacity } \\
\left(\mathrm{mg} \mathrm{g}^{-1}\right)\end{array}$ & References \\
\hline 1. & Chitosan flakes & - & 22.09 & Aydin and Aksoy (2009) \\
2. & Aminated chitosan & 90 & 28.7 & Yan et al. (2007) \\
3. & Ethylene diamine modified chitosan & 90 & 48.78 & Hu et al. (2011) \\
4. & Sulphate-crosslinked chitosan & 85 & 157 & Kahu et al. (2014) \\
5. & Ionic liquid-impregnated chitosan & 86.94 & 63.69 & Kumar et al. (2012) \\
6. & TBA-SCC (present study) & 85 & 225.9 & (present study) \\
\hline
\end{tabular}


respectively. Adsorption process is spontaneous at room temperature for detoxifying hexavalent chromium. The reusability of TBA-SCC with high adsorption capacity makes it a greener material for $\mathrm{Cr}(\mathrm{VI})$ removal from industrial effluents.

Acknowledgments The authors are thankful to RTM Nagpur University for University Research Project No. Dev/1336 (2014-16).

\section{References}

Aydin YA, Aksoy ND (2009) Adsorption of chromium on chitosan: optimization, kinetics and thermodynamics. Chem Eng J 151:188-194

Bhatnagar A, Sillanpaa M (2009) Applications of chitin- and chitosan-derivatives for the detoxification of water and wastewater-a short review. Adv Colloid Interface Sci 152:26-38

Bulut E, Ozacar M, Sengil IA (2008) Adsorption of malachite green onto bentonite: equilibrium and kinetic studies and process design. Microporous Mesoporous Mater 115:234-246

Crini G, Peindy HN, Gimbert F, Robert C (2007) Removal of CI basic green 4 (Malachite Green) from aqueous solution by adsorption using cyclodextrin based adsorbent: kinetic and equilibrium studies. Sep Purif Technol 53:97-110

Debnath S, Maity A, Pillay K (2014) Magnetic chitosan-go nanocomposite: synthesis, characterization and batch adsorber design for Cr(VI) removal. J Environ Chem Eng 2:963-973

Devi MG, Al-Hashmi ZSS, Sekhar GC (2012) Treatment of vegetable oil mill effluent using crab shell chitosan as adsorbent. Int J Environ Sci Technol 9(4):713-718

Donia AM, Atia AA, El-Boraey HA, Mabrouk D (2006) Uptake studies of copper(II) on glycidyl methacrylate chelating resin containing $\mathrm{Fe}_{2} \mathrm{O}_{3}$ particles. Sep Purif Technol 49:64-70

Dubinin MM, Radushkevich LV (1947) The equation of the characteristic curve of the activated charcoal. Proc Acad Sci USSR Phys Chem Sect 55:331-337

Elwakeel KZ (2014) Removal of arsenate from aqueous media by magnetic chitosan resin immobilized with molybdate oxoanions. Int J Environ Sci Technol 11(4):1051-1062

Freundlich HMF (1906) Over the adsorption in solution. Z Phys Chem 57:385-470

Hayes BL (2004) Recent advances in microwave-assisted synthesis. Aldrichimica Acta 37(2):66-76

Ho YS (2006) Review of second-order models for adsorption systems. J Hazard Mater B 136:681-689

Houk KN, Leach AG, Kim SP, Zhang X (2003) Binding affinities of host-guest, protein-ligand, and protein-transition-state complexes. Angew Chem Int Ed 42:4872-4897

Hu XJ, Wang JS, Liu YG, Li X, Zeng GM, Bao ZL, Zeng XX, Chen AW, Long F (2011) Adsorption of chromium(VI) by ethylenediamine-modified cross-linked magnetic chitosan resin: isotherms, kinetics and thermodynamics. J Hazard Mater 185:306-314
Kahu S, Saravanan D, Jugade R (2014) Effective detoxification of hexavalent chromium using sulfate-crosslinked chitosan. Water Sci Technol 70:2047-2055

Kalidhasan S, Gupta PA, Cholleti VR, Kumar ASK, Rajesh V, Rajesh N (2012) Microwave assisted solvent free green preparation and physicochemical characterization of surfactant-anchored cellulose and its relevance toward the effective adsorption of chromium. J Colloid Interface Sci 372:88-98

Katz SA, Salem H (2006) The toxicology of chromium with respect to its chemical speciation: a review. J Appl Toxicol 13:217-224

Kumar ASK, Rajesh N (2013) Exploring the interesting interaction between grapheme oxide, Aliquat-336 (a room temperature ionic liquid) and chromium(VI) for wastewater treatment. RSC Adv 3:2697-2709

Kumar ASK, Gupta T, Kakan SS, Kalidhasan S, Manasi S, Rajesh V, Rajesh N (2012) Effective adsorption of hexavalent chromium through a three centre (3c) co-operative interaction with an ionic liquid and biopolymer. J Hazard Mater 239-240:213-224

Kumar ASK, Kumar CU, Rajesh V, Rajesh N (2014a) Microwave assisted preparation of $n$-butylacrylate grafted chitosan and its application for $\mathrm{Cr}(\mathrm{VI})$ adsorption. Int $\mathrm{J}$ Biol Macromol 66:135-143

Kumar ASK, Sharma S, Reddy RS, Barathi M, Rajesh N (2014b) Comprehending the interaction between chitosan and ionic liquid for the adsorption of palladium. Int $\mathrm{J}$ Biol Macromol 72:633-663

Kumar ASK, Jiang SJ, Tseng WL (2015) Effective adsorption of chromium(VI)/Cr(III) from aqueous solution using ionic liquid functionalized multiwalled carbon nanotubes as a super sorbent. J Mater Chem A. doi:10.1039/c4ta06948j

Kyzas GZ, Bikiaris DN (2015) Recent modifications of chitosan for adsorption applicatons: a critical and schematic review. Mar Drugs 13:312-337

Lagergren S (1898) Zur theorie der sogennanten adsorption geloster Stoffe. K. Sven. Vetenskapsakad. Handlingar 24:1-39

Langmuir I (1918) The adsorption of gases on plane surface of glass, mica and platinum. J Am Chem Soc 40:1361-1403

Lewinsky AA (2007) Hazardous materials and wastewater: treatment, removal and analysis. Nova Publishers, New York

Mayyas MA (2012) Properties of chitosan nanoparticles formed using sulphate anions as crosslinking bridges. Am J Appl Sci 9:1091-1100

Mendham VJ, Denny RC, Barnes JD, Thomas MJK (2002) Vogel's textbook of quantitative chemical analysis, 6th edn. Pearson Education, Singapore

Rajesh N, Krishna Kumar AS, Kalidhasan S, Rajesh V (2011) Trialkylamine impregnated macroporous polymeric sorbent for the effective removal of chromium from industrial wastewater. Chem Eng Data 56:2295-2304

Shekhawat A, Kahu S, Saravanan D, Jugade R (2015) Synergistic behavior of ionic liquid impregnated sulphate crosslinked chitosan towards adsorption of $\mathrm{Cr}(\mathrm{VI})$. Int $\mathrm{J}$ Biol Macromol 80:615-626

Shekhawat A, Kahu S, Saravanan D, Jugade R (2016) Assimilation of chitin with tin for defluoridation of water. RSC Adv. doi:10. 1039/C6RA00014B 
Tirgar A, Golbabaei F, Hamedi J, Nourijelyani K, Shahtaheri SJ, Moosavi SR (2006) Removal of airborne hexavalent chromium mist using chitosan gel beads as a new control approach. Int J Environ Sci Technol 3(3):305-313

Weber WJ, Morris JC (1963) Kinetics of adsorption on carbon from solution. J Sanit Eng Div Am Soc Civil Eng 89:3-60
Yan Z, Haijia S, Tianwei T (2007) Adsorption behaviors of the aminated chitosan adsorbent. Korean J Chem Eng 24:1047-1052

Zhu L, Liu Y, Chen J (2009) Synthesis of $N$-methylimidazolium functionalized strongly basic anion exchange resins for adsorption of Cr(VI). Ind Eng Chem Res 48:3261-3267 